\title{
Erratum to: Endoscopic Management of Double Esophageal Perforation by Ingested Foreign Body Using Over-the-Scope Clip: A Case Report
}

Prasanta Debnath ${ }^{1}$ Pravin Rathi ${ }^{1}$ Sujit Nair ${ }^{1}$ Suhas Udgirkar ${ }^{1}$ Sanjay Chandnani ${ }^{1}$ Vinay Pawar ${ }^{1}$

${ }^{1}$ Department of Gastroenterology, Topiwala National Medical College and Bai Yamunabai Laxman Nair Charitable Hospital, Mumbai, Maharashtra, India

\section{Erratum}

J Digest Endosc 2020;11:e1

\begin{abstract}
Address for correspondence Prasanta Debnath, MD, Department of Gastroenterology, Topiwala National Medical College and Bai Yamunabai Laxman Nair Charitable Hospital, Room no 717, 7th floor, OPD Building, Dr A.L Nair Road, Mumbai Central, Mumbai 400008, Maharashtra, India (e-mail: prasantad89@gmail.com).
\end{abstract}

Publisher regrets to inform that in the above-mentioned article Dr Vinay Pawar's name was missed inadvertently from the authors' list. The article was published on efirst on July 3,2020 . DOI of the original article is: $10.1055 / \mathrm{s}-0040-1713551$. Corrected author list appears as above. 